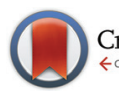

CrossMark

\&lick for updates

Cite this: Food Funct., 2016, 7, 110

Received 28th April 2015,

Accepted 21st September 2015

DOI: $10.1039 / \mathrm{c} 5$ fo00458f

www.rsc.org/foodfunction

\title{
Bioaccessibility study of plant sterol-enriched fermented milks
}

\author{
Silvia Vaghini, Antonio Cilla, Guadalupe Garcia-Llatas and María Jesús Lagarda*
}

The bioaccessibility (BA) of total and individual plant sterols (PS) of four commercial PS-enriched fermented milk beverages (designated as A to D) was evaluated using in vitro gastrointestinal digestion including the formation of mixed micelles. The fat content of the samples ranged from 1.1 to $2.2 \%(\mathrm{w} / \mathrm{w})$, and PS enrichment was between 1.5 and $2.9 \%(\mathrm{w} / \mathrm{w}) . \beta$-Sitosterol, contained in all samples, was higher in samples A and B (around $80 \%$ of total PS). The campesterol content was C $(22 \%)>A(7 \%)>B(5 \%)$. Sitostanol was the most abundant in sample D $(85 \%)$. Stigmasterol was only present in sample $C(33 \%)$. The greatest BA percentage for total PS corresponded to samples A and B (16-17\%), followed by sample D (11\%) and sample $C(9 \%)$. The total BA was not related to the protein, lipid or PS content of the beverages, whereas samples with higher carbohydrates and fiber contents showed lower BA. The BA of the individual PS differed according to the sample considered, and was not related to the PS profile of the sample, thus indicating strong dependency upon the matrix (PS ingredient and other components). Although in vivo studies should be carried out to better assess the functionality of PS in functional foods such as enriched fermented milk beverages, our in vitro study is a useful preliminary contribution to evaluation of the efficacy of these products.

\section{Introduction}

Plant sterols (PS) (phytosterols and phytostanols) are of considerable interest due to their positive effects on human health. The daily intake of $1.5-3 \mathrm{~g}$ of PS could reduce total cholesterol by $5-15 \%$ and LDL-cholesterol by $10-20 \%$ in hypercholesterolemic individuals. Since the Western diet could supply a maximum of $440 \mathrm{mg}$ of PS per day, the addition of PS (free or esterified with fatty acids) to foods offers a way of reaching the optimal dose of $2 \mathrm{~g}$ per day. ${ }^{1,2}$

The European Atherosclerosis Society (EAS) Consensus Panel, based on data referred to the lowering of LDL-cholesterol and the absence of adverse signs (associated with a PS intake of $2 \mathrm{~g}$ per day), concluded that functional foods with PS may be considered in individuals with high cholesterol levels at intermediate or low global cardiovascular risk who do not qualify for drug treatment, as an adjunct to therapy in high and very high risk patients who fail to achieve LDL-cholesterol targets with statins or who are statin-intolerant, and in adults and children ( $>6$ years of age) with familial hypercholesterolemia. ${ }^{2}$ However, this higher PS intake consequently increases serum PS concentrations, and the relationship between higher

Nutrition and Food Science Area, Faculty of Pharmacy, University of Valencia, Avda. Vicente Andrés Estellés s/n, 46100 - Burjassot (Valencia), Spain.

E-mail: m.j.lagarda@uv.es; Fax: +34-963544954; Tel: +34-963544909 serum levels and cardiovascular risk remains a subject of controversy. $^{3}$

Health claims have been approved for these functional foods ${ }^{4-6}$ referring to the beneficial effects of phytosterols and phytostanols in managing blood cholesterol levels. Different hypotheses have been proposed to explain this PS-mediated hypocholesterolemic effect - the most widely cited mechanism being competition between cholesterol and PS for incorporation into mixed micelles in the intestinal tract, which is the first step for absorption into enterocytes. The greater hydrophobicity of PS, due to the presence of an extra carbon chain in the C-24 position, compared with cholesterol, facilitates PS incorporation into the micelles and the displacement of cholesterol. $^{7,8}$ The intestinal hydrolysis of PS esters through digestive enzyme action seems to be a crucial step for their incorporation into the micelles, and therefore for their cholesterol-lowering effects. ${ }^{9}$

From a functional perspective, it is interesting to determine the effectiveness of PS-enriched foods, since the food matrix and the composition of the ingredients used as a PS source affect their bioavailability, and therefore the functionality. Variabilities in the effectiveness of LDL-cholesterol reductions obtained in clinical studies have highlighted some factors that can affect the effectiveness of PS, such as food matrix (comprising: macronutrient composition, presence of emulsifiers or other (bioactive) compounds, food carrier - spreads, dairy, etc., among others), number of servings per day, time of 
intake, consumption as a snack or with a meal, origin of PS employed for enrichment, etc. ${ }^{7,10-12}$ For instance, it has been found that milk and yoghurt allow greater reduction of LDLcholesterol compared to bread and cereal, ${ }^{13}$ also the intake of a single dose of a PS-enriched yoghurt drink with lunch resulted in a larger decrease in LDL-cholesterol levels than the same dose provided before breakfast, ${ }^{14}$ and the simultaneous presence of other bioactive compounds such as $\beta$-cryptoxanthin in a milk-based fruit beverage improves the cholesterollowering effect of PS. ${ }^{15}$ Regarding the ingredients used for PS enrichment, the latter can be isolated from tall oil or vegetable oils, which have qualitatively and quantitatively distinct PS profiles, and differences in absorption and metabolism have been observed depending on the PS considered. ${ }^{1,12,16}$ In this sense, it has been reported that a higher ratio of $\beta$-sitosterol to campesterol (or $\beta$-sitostanol to campestanol) in the PS ingredient may enhance the reduction in LDL-cholesterol. ${ }^{11}$

In vitro and in vivo methods can be used for the evaluation of bioavailability. In vivo methods usually provide the most accurate results, but are time consuming and costly. In vitro techniques simulating gastrointestinal digestion can be used to produce a bioaccessible fraction (BF) containing the compounds potentially absorbable by enterocytes, and such studies are accepted as a predictive model for screening and building new hypotheses prior to clinical assays in humans. ${ }^{17}$ The bioaccessibility (BA) of a food component is thus defined as its content in the $\mathrm{BF}$ with respect to its total content in the food. In the case of PS, a greater percentage BA means greater incorporation into the mixed micelles, and thus greater cholesterol displacement from the latter.

A review of the literature has yielded only two studies addressing the effect of a gastrointestinal digestion model on PS in commercial food-grade mixtures of PS esters ${ }^{18}$ and in non-commercial enriched fruit and/or milk beverages, ${ }^{19}$ with the description of a matrix influence in both cases.

To our knowledge, no studies have assessed BA from commercial PS-enriched products. In this regard, dairy product drinks such as fermented milks are very popular among consumers, as they are one-daily dose products. Our group has found products of this kind to have a diverse lipid profile, ${ }^{20}$ and possibly also different PS sources. The aim of the present study was to compare the BA of PS from four commercial PSenriched fermented milk beverages using an in vitro gastrointestinal digestion model including the formation of mixed micelles.

\section{Materials and methods}

\section{Samples}

Four different commercial fermented milk beverages enriched with PS (designated A to D) from three different batches were bought from local supermarkets (Valencia, Spain). Samples A, $\mathrm{B}$ and $\mathrm{C}$ contained phytosterols, and sample D contained phytostanols. The ingredients and nutritional information (per $100 \mathrm{~g}$ of product) as described on the labeling of the samples are shown in Table 1. Samples were stored in their original containers refrigerated (between 2 and $4{ }^{\circ} \mathrm{C}$ ) until analysis, which was performed before their expiry date. For each sample, two units from each batch were homogenized for the collection of aliquots for analysis.

\section{Reagents}

Sterol standards used were $5 \beta$-cholestan- $3 \alpha$-ol (epicoprostanol)

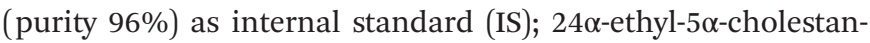
$3 \beta$-ol (stigmastanol) (purity 97\%); (24S)-ethylcholest-5,22-dien$3 \beta$-ol (stigmasterol) (purity 97\%); and (24R)-ethylcholest-5-en$3 \beta$-ol ( $\beta$-sitosterol) (purity 97.3\%), purchased from Sigma Chemical Co. [St. Louis, MO, USA]. (24R)-Methylcholest-5-en$3 \beta$-ol (campesterol) (purity 94\%) was from Steraloids [Newport, RI, USA].

For in vitro digestion we used $\alpha$-amylase from human saliva; bovine bile, bovine serum albumin (BSA), calcium chloride dehydrate, and cholesterol esterase from bovine pancreas; colipase from porcine pancreas; glucose, glucosamine hydrochloride, glucuronic acid, and lipase from human pancreas; magnesium chloride and mucin from porcine stomach type II; sodium dihydrogen phosphate and pancreatin from porcine pancreas; pepsin from porcine stomach; phospholipase $\mathrm{A}_{2}$ from porcine pancreas; potassium thiocyanate, sodium taurocholate, and tris(hydroxymethyl)aminomethane, from Sigma Chemical Co. [St. Louis, MO, USA].

Ammonium chloride, hydrochloric acid (purity 37\%), chloroform, ethanol, methanol, potassium chloride $(\mathrm{KCl})$, sodium chloride, sodium bicarbonate, potassium dihydrogen phosphate, anhydrous sodium sulfate and urea were supplied by Merck [Whitehouse Station, NJ, USA]. Butylhydroxytoluene (BHT) and hexamethyldisilazane (HMDS) were from Sigma Chemical Co. (St. Louis., MO, USA). Diethyl ether, $n$-hexane, potassium hydroxide $(\mathrm{KOH})$ and 2-propanol were from Scharlau [Barcelona, Spain]; uric acid was purchased from Prolabo [Sacramento, CA, USA]; and sodium hydroxide was from Panreac [Barcelona, Spain]. Anhydrous pyridine was purchased from Acros Organics [Geel, Belgium], whereas trimethylchlorosilane (TMCS) was from Fluka [Buchs, Switzerland]. A Millipore Q water purification system was used to obtain ultrapure water.

\section{Methods}

\section{Determination of PS}

A previously validated method for milk-based beverages ${ }^{16,21}$ was used for PS determination. A sample amount providing approximately $40 \mathrm{mg}$ of PS was taken. A modification of the method of Folch et al. ${ }^{22}$ was used for lipid extraction. Twentyfive $\mathrm{mL}$ of chloroform/methanol $(1: 1, \mathrm{v} / \mathrm{v})$ containing $0.05 \%$ BHT was added to the sample, and the mixture was homogenized (Polytron PT 2000, Kinematica AC, Switzerland) for three minutes at $250 \mathrm{~W}$. After adding $12.5 \mathrm{~mL}$ of chloroform and mixing again with the Polytron, the sample was filtered 
Table 1 Fermented milk beverages enriched with plant sterols: ingredients and nutritional labeling

\begin{tabular}{|c|c|c|c|c|}
\hline Samples & $\begin{array}{l}\text { Fermented skimmed milk } \\
\text { with sweeteners, added plant } \\
\text { sterols and strawberry }\end{array}$ & $\begin{array}{l}\text { Fermented milk sweetened } \\
\text { and aromatized with plant } \\
\text { sterol esters }\end{array}$ & $\begin{array}{l}\text { C } \\
\text { Fermented skimmed milk } \\
\text { with sugar, with orange juice } \\
\text { from concentrate, and plant } \\
\text { sterols added }\end{array}$ & $\begin{array}{l}\text { D } \\
\text { Fermented skimmed milk } \\
\text { with plant stanols, without } \\
\text { sugar added, without lactose } \\
\text { and with sweeteners }\end{array}$ \\
\hline Ingredients & $\begin{array}{l}\text { Skimmed milk, plant sterols } \\
\text { ester (2.6\%, of which } 1.6 \% \\
\text { corresponds to free plant } \\
\text { sterol), food fiber } \\
\text { (oligofructose), strawberry } \\
\text { (1\%), skimmed powdered } \\
\text { milk, whey protein, stabilizers } \\
\text { (modified corn starch, pectin } \\
\text { and guar gum), aroma, } \\
\text { natural colorant (E-120), } \\
\text { sweeteners (acesulfame-K and } \\
\text { sucralose) and active lactic } \\
\text { ferments }\end{array}$ & $\begin{array}{l}\text { Skimmed milk ( } 76 \%), \\
\text { water, PS esters ( } 3.4 \%), \\
\text { modified corn starch, } \\
\text { thickeners (pectin and guar } \\
\text { gum), skimmed powdered } \\
\text { milk, lactic ferments, } \\
\text { aromas, sweeteners } \\
\text { (sucralose and potassium } \\
\text { acesulfame), preservative } \\
\text { (potassium sorbate) }\end{array}$ & $\begin{array}{l}\text { Skimmed milk, sugars }(7.6 \%) \text {, } \\
\text { orange juice from concentrate } \\
\text { (5\%), corn dextrose } 2.5 \% \text {, PS } \\
\text { esters } 2.5 \% \text { (1.5\% free PS), } \\
\text { food fiber: inulin } 1 \% \text {, milk } \\
\text { proteins, stabilizer: guar gum, } \\
\text { colorant: beta-carotene, } \\
\text { antioxidant: ascorbic acid, } \\
\text { acidulant: citric acid, aroma, } \\
\text { Lactobacillus acidophilus } \\
\text { (LA5®), Bifidobacterium } \\
\text { (BB12®) }\end{array}$ & $\begin{array}{l}\text { Skimmed milk, plant stanol } \\
\text { esters ( } 5 \% \text {, equivalent to } \\
2.9 \% \text { plant stanols), food } \\
\text { fiber (oligofructose), } \\
\text { modified corn starch, lactase, } \\
\text { stabilizer (pectin), aroma, } \\
\text { sweetener (sucralose, } \\
\text { aspartame and acesulfame } \\
\text { K), lemon juice, vitamins (B6 } \\
\text { and folic acid) and lactic } \\
\text { ferments }\end{array}$ \\
\hline Proteins (g) & 3.3 & 2.7 & 2.9 & 2.7 \\
\hline $\begin{array}{l}\text { Carbohydrates } \\
\text { (g) }\end{array}$ & 4.5 & 3.9 & 14.7 & 3.6 \\
\hline Sugars $(g)$ & 4.4 & 3.2 & 14.4 & 3.2 \\
\hline Fat $^{a}(\mathrm{~g})$ & 1.1 & 1.4 & 1.4 & 2.2 \\
\hline SFA (g) & 0.1 & 0.1 & 0.4 & 0.2 \\
\hline MUFA (g) & 0.7 & 0.8 & - & 1.4 \\
\hline PUFA (g) & 0.3 & 0.5 & - & 0.6 \\
\hline $\operatorname{PS}^{b}(\mathrm{~g})$ & 1.6 & 2 & 1.5 & $2.9^{c}$ \\
\hline Fiber $(\mathrm{g})$ & 0.7 & 0 & 1 & 1.3 \\
\hline Sodium (g) & 0.05 & 0.04 & 0.04 & $<0.1$ \\
\hline Calcium (mg) & 124 & - & - & - \\
\hline
\end{tabular}

${ }^{a}$ Sterols not included in total fat. ${ }^{b}$ Expressed as free sterols, not esterified. ${ }^{c}$ Phytostanols, in this sample. SFA: saturated fatty acids; MUFA: monounsaturated fatty acids; PUFA: polyunsaturated fatty acids; PS: plant sterols.

(Whatman no. 1, $90 \mathrm{~mm}$ ) through a Buchner funnel. Fifteen $\mathrm{mL}$ of a $1 \mathrm{~N} \mathrm{KCl}$ solution was added to the filtrate and refrigerated overnight $\left(4^{\circ} \mathrm{C}\right)$. After separation of the organic fraction, the chloroform phase was concentrated in a rotary evaporator and dried under a nitrogen stream. A fraction (1/20) of the extracted fat was taken in triplicate, and $200 \mu \mathrm{g}$ of IS was added to each aliquot. Hot saponification ${ }^{16,21,23}$ was performed at $65{ }^{\circ} \mathrm{C}$ for one hour with $2 \mathrm{~mL}$ of a $1 \mathrm{~N} \mathrm{KOH}$ in ethanol/Milli Q-water $(9: 1)$ solution. The unsaponifiable material was then extracted with diethyl ether and subjected to derivatization with HMDS:TMCS in anhydrous pyridine $(2: 1: 5, \mathrm{v} / \mathrm{v} / \mathrm{v})\left(40^{\circ} \mathrm{C}\right.$ for 25 minutes). The trimethylsilyl ether (TMSE) derivatives were solubilized in $n$-hexane, filtered (syringe driven Millex FH with filter $1 \mathrm{~mL}, 0.45 \mu \mathrm{m}$, Millipore, Milford, MA, USA) and evaporated with nitrogen. The TMSE derivatives were then dissolved in $250 \mu \mathrm{L}$ of $n$-hexane and analyzed by gas chromatography-flame ionization detection (GC-FID) under the same conditions described by GonzálezLarena et al. ${ }^{16}$ Analysis was performed in triplicate.

The quantification of phytosterols was performed with calibration curves containing $200 \mu \mathrm{g}$ of IS and the corresponding commercial standards (campesterol, stigmasterol, and $\beta$-sito- sterol), whereas phytostanol quantification was performed from the stigmastanol (only phytostanol standard commercialized) calibration curve (with $200 \mu \mathrm{g}$ of IS). The calibration equations employed were: campesterol (24.91-399.97 $\mu \mathrm{g} ; y=$ $0.0073 x-0.0391, r=0.998)$, stigmasterol (14.95-1998.98 $\mu \mathrm{g}$; $y=0.0056 x-0.0918, r=0.999), \beta$-sitosterol $(25.3-3000.58 \mu \mathrm{g} ;$ $y=0.0063 x-0.2688, \quad r=0.999)$ and stigmastanol (9.99-1499.62 $\mu \mathrm{g} ; y=0.0062 x+0.1628, r=0.998)$.

\section{Bioaccessibility of PS}

Simulated gastrointestinal digestion was performed according to Granado-Lorencio et al. ${ }^{24}$ modified by Garcia-Llatas et al. ${ }^{12}$ and Alemany et al. ${ }^{19}$ Digestion was performed in three phases, salivary, gastric and intestinal, with the formation of mixed micelles. Twenty $\mathrm{g}$ of sample (in quadruplicate) was transferred to an Erlenmeyer flask, and a saliva solution $(9 \mathrm{~mL}$, pH $6.5 \pm 0.2)$ containing organic and inorganic components and $\alpha$-amylase $(0.19 \mathrm{mg})$ was added. The mixture was incubated in a shaking water bath (SBS30 Stuart Scientific) for 5 minutes at $37^{\circ} \mathrm{C}$ and 95 orbits per minute (opm). Afterwards, $13.5 \mathrm{~mL}$ of gastric juice $(\mathrm{pH} 1.07 \pm 0.07)$ containing organic and inorganic solutions, mucin, BSA and pepsin from 
porcine stomach were added, and the mixture was incubated under the same shaking bath conditions for one hour. Then, $25 \mathrm{~mL}$ of duodenal juice $(\mathrm{pH} 7.8 \pm 0.2)$ and $9 \mathrm{~mL}$ of bile solution ( $\mathrm{pH} 8.0 \pm 0.2$ ) were added and, after neutralization of the sample $\mathrm{pH}$ (6.8-7.2), human pancreatic lipase (1 U), colipase (12.5 $\mu \mathrm{g})$, cholesterol esterase (5 U), phospholipase $\mathrm{A}_{2}$ (501.2 U) and sodium taurocholate $(0.02 \mathrm{mg})$ were added. The flasks were incubated for two hours $\left(37^{\circ} \mathrm{C}\right.$ and $\left.95 \mathrm{opm}\right)$ and the digested samples were centrifuged for 90 minutes at $4{ }^{\circ} \mathrm{C}$ at $3100 \mathrm{~g}$ to obtain the aqueous-micellar fraction (supernatants) considering the BF.

Five $\mathrm{g}$ of the collected BF were added with $200 \mu \mathrm{g}$ of IS and saponified (with $10 \mathrm{~mL}$ of a $2 \mathrm{~N} \mathrm{KOH}$ solution in $90 \%$ ethanol) at $65{ }^{\circ} \mathrm{C}$ for one hour. The unsaponifiable material was then extracted with diethyl ether, and all of it was used for PS quantification using the same derivatization and determination conditions described for PS determination.

\section{Statistical analysis}

One-way analysis of variance (ANOVA) was used to determine statistically significant differences $(p<0.05)$ between the contents in the same compound (individual or total PS) and in the same type of sample (beverage or BF or BA) (within lines) or in the BA of the same sample (A or B or C or D) (within columns). Statgraphics Plus version 5.1 (Statistical Graphics Corp., Rockville, MD, USA) was used.

\section{Results and discussion}

\section{Determination of PS}

The GC-FID chromatograms of the PS identified in samples A, $\mathrm{C}$ and $\mathrm{D}$ are shown in Fig. 1 (the profile of sample $\mathrm{B}$ is not shown due to its similarity to that of sample A). Table 2 shows the PS contents (mg per $100 \mathrm{~g}$ of fermented milk beverage). The lowest total PS content corresponded to sample C (1072 mg per $100 \mathrm{~g}$ ), while the highest contents were detected in samples A (1546 mg per $100 \mathrm{~g}$ ) and D (1756 mg per $100 \mathrm{~g}$ ).

Regarding the PS profiles in the analyzed beverages, samples A and B contained campesterol, $\beta$-sitosterol and sitostanol. Sample $\mathrm{C}$ also contained campesterol and $\beta$-sitosterol, but differed from $\mathrm{A}$ and $\mathrm{B}$ in that it also presented stigmasterol. Sample D, had campestanol, $\beta$-sitosterol and sitostanol.

$\beta$-Sitosterol, contained in all samples, was higher in samples A and B (around 1200-1250 mg per $100 \mathrm{~g}$, or $80 \%$ of total PS), followed by sample C (45\%) and sample D (4\%). The campesterol content was C $(22 \%)>$ A $(7 \%)>$ B (5\%). Sitostanol was the most abundant in sample D (being $85 \%$ of total PS), while samples A and B had the same amount (around 12\%), and sample $\mathrm{C}$ contained no sitostanol. Stigmasterol was only contained in sample C (33\%). The similarity in terms of the type and amount of PS found in samples A and B suggest that the same or a similar source of PS was used in their manufacture.

In general, the lesser total PS content recorded with respect to the content stated on the labeling may have been due to a possible tendency of PS to adhere to the inside of the container or to precipitate. It must be remembered that PS are added to foods in the form of an ingredient that contains more components that might influence their behavior. ${ }^{16}$

The differences found in the PS profile among samples A, B and $\mathrm{C}$ (enriched with phytosterols) with respect to those reported in the literature could be attributed to the origin of the PS used in enrichment, as confirmed by González-Larena et $a l .{ }^{16}$ for several PS ingredients. In this sense, the major presence of $\beta$-sitosterol, followed by sitostanol and campesterol, in similar proportions, in samples A and B indicates the use of a tall oil-derived sterol ingredient in their formulation, while the greater presence of stigmasterol in sample $\mathrm{C}$ is indicative of the use of a soybean oil containing-ingredient. Saraiva et al. ${ }^{25}$ analyzed the PS contents in 7 different brands of yoghurts on the Portuguese market, $\beta$-sitosterol being the most abundant (65-71\%), followed by sitostanol and campesterol in 6 of them, as in samples A and B of our study. There was only one brand, enriched with phytostanols, in which sitostanol and campestanol were the only detected PS (75\% and 25\%, respectively), with great differences versus the PS profile shown by our sample D. Other studies involving samples also from the European market reveal heterogeneity in the PS profiles. In this regard, a recent study ${ }^{26}$ has reported a PS profile $(\beta$-sitosterol $80 \%>$ sitostanol $13 \%>$ campesterol $7 \%$ ) similar to that of samples A and B corresponding to a fermented milk analyzed using a novel fast-GC mass spectrometry method. However, a different PS profile ( $\beta$-sitosterol $70-73 \%>$ campesterol $12-15 \%$ > sitostanol 9-12\%) has been described by Barnsteiner et al. ${ }^{27}$ for two brands of drinking yoghurts. In another study, Laakso et al. ${ }^{28}$ analyzed a stanyl fatty acid ester-enriched yoghurt in which sitostanol and campestanol were the most abundant PS. However, the corresponding unsaturated PS ( $\beta$-sitosterol and campesterol) were also detected.

According to the European Union (EU) regulations, PSenriched foods must contain a minimum PS concentration of $0.8 \mathrm{~g}$ in a daily dose, with a maximum of $3 \mathrm{~g}$ per day. The daily vending size contained $100 \mathrm{~g}$ of fermented milk in samples A, $\mathrm{B}$ and $\mathrm{C}$, and $65 \mathrm{~g}$ in sample D. Thus, each sample satisfied the maximum and minimum limits. Moreover, as can be seen in Table 2, beverages A, B and C generally comply with the PS profiles specified by the European Commission for yoghurttype products, since the PS relative percentages of each phytosterol abide with the legal specifications: $<80 \% \beta$-sitosterol, $<40 \%$ campesterol, $<30 \%$ stigmasterol, $<3 \%$ brassicasterol, $<15 \%$ sitostanol, $<5 \%$ campestanol, and $<3 \%$ other sterols/ stanols. $^{29,30}$ However, sample D presented the quantities of campestanol and sitostanol far above those specified by the EU, since plant stanol-enriched foods do not need novel food authorization, as they were already used in the EU before the implementation of this legislation. ${ }^{31,32}$

\section{Bioaccessibility of PS}

The PS contents in the BF of the samples, expressed as mg per $100 \mathrm{~g}$ of fermented milk beverage, and their corresponding BA are shown in Table 2. 
(a) Sample A

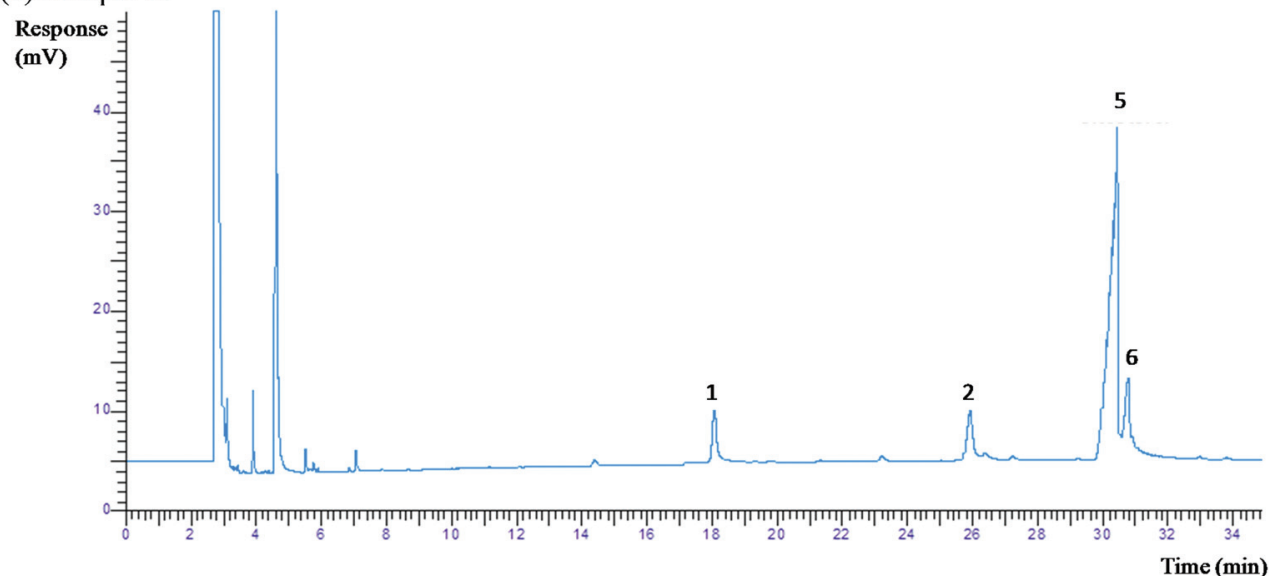

(b) Sample C

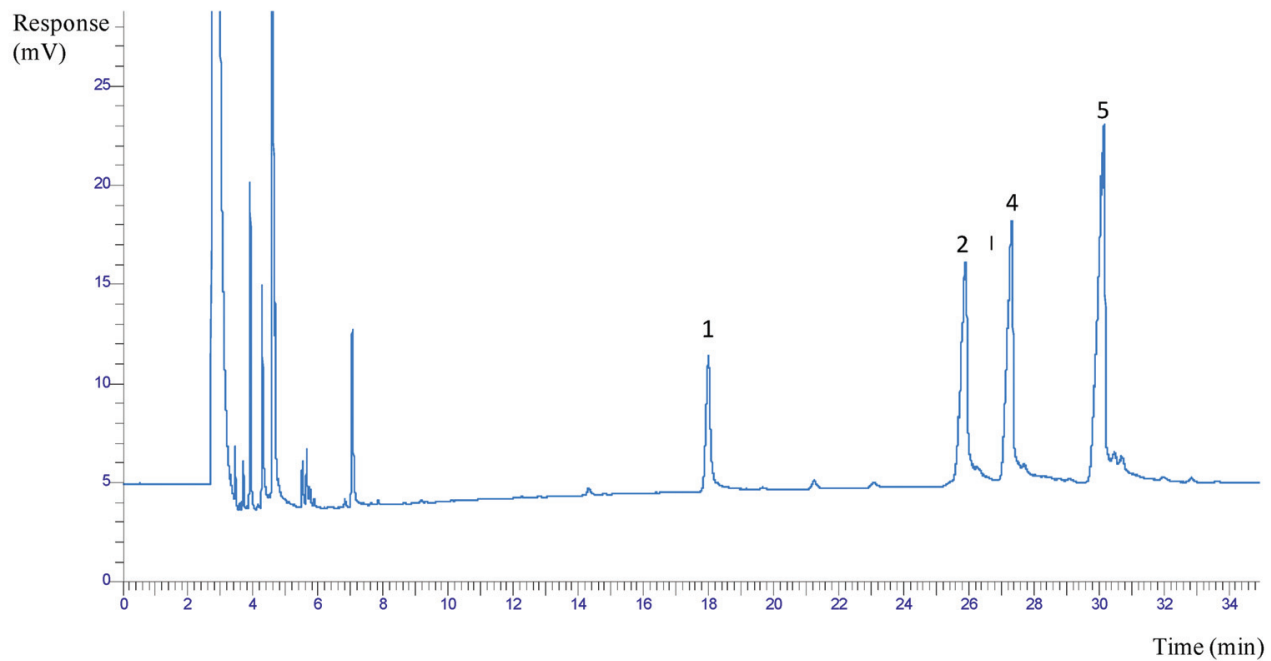

(c) Sample D

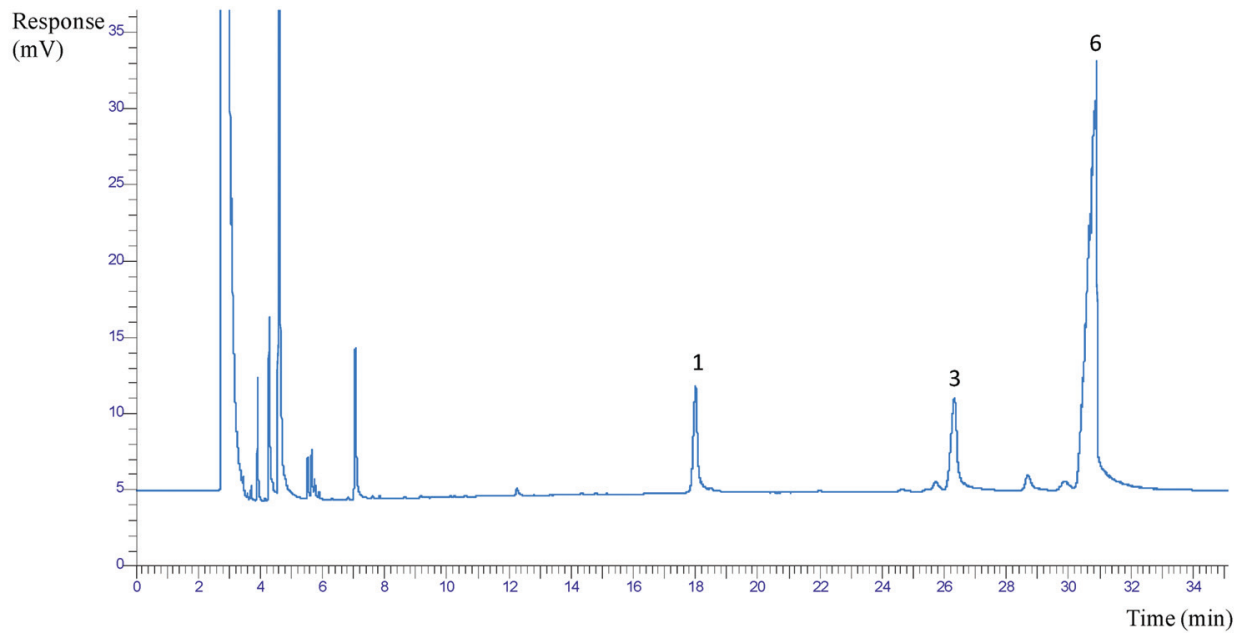

Fig. 1 GC-FID chromatogram of the PS identified in samples A (a), C (b) and D (c). 1: epicoprostanol (IS) (retention time (RT): 18 min); 2 : campesterol (RT: $25.9 \mathrm{~min}$ ); 3: campestanol (RT: $26.3 \mathrm{~min}$ ); 4: stigmasterol (RT: $27.3 \mathrm{~min}) ;$ 5: $\beta$-sitosterol (RT: $30.3 \mathrm{~min}) ; 6:$ sitostanol (RT: $30.6 \mathrm{~min})$. 


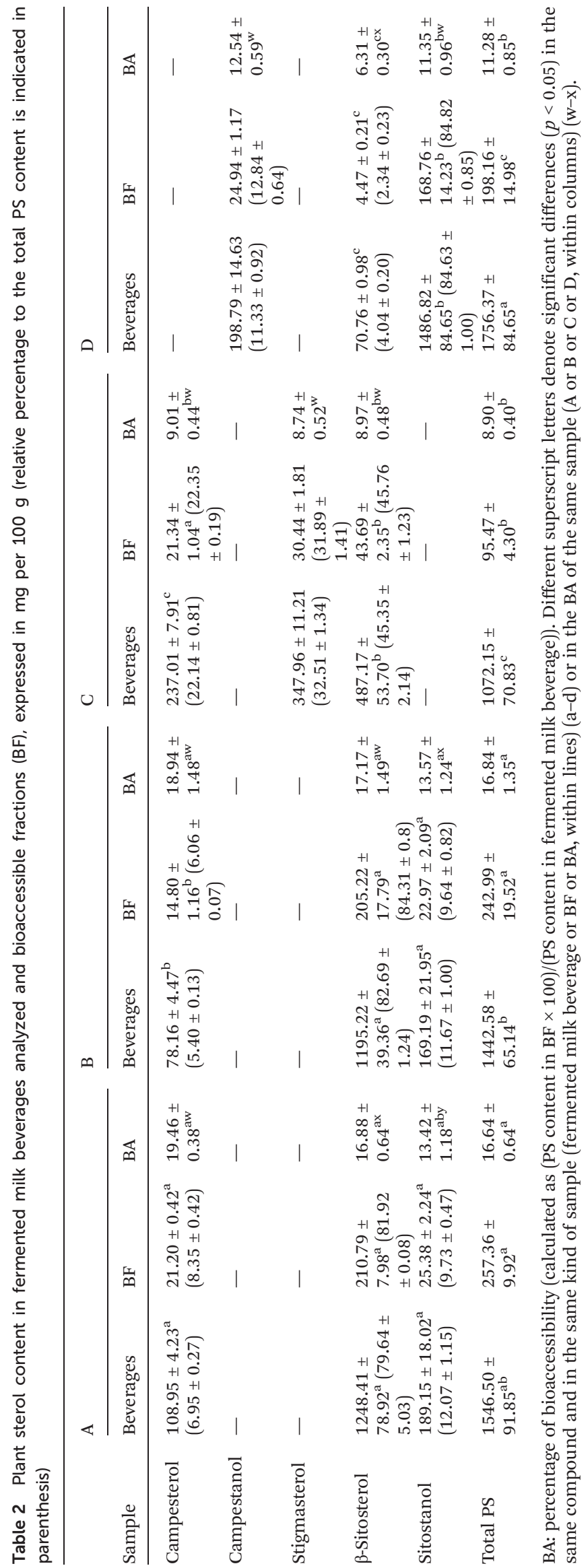

A statistically significant decrease in the PS content $(p<0.05)$ among beverages after digestion was observed in the BF (95-257 mg per $100 \mathrm{~g}$ of sample); the highest total PS amount in the BF was detected in samples A and B, followed by $\mathrm{D}>\mathrm{C}$. The order of PS contents in the BF was similar to that determined in the original samples. The relative PS percentages of each PS after the digestion process changed, increasing for campesterol in samples A and B, and decreasing for $\beta$-sitosterol in sample D.

The greatest BA for total PS corresponded to samples A and B (16-17\%), followed by sample D (11\%) and sample C (with a similar percentage of $9 \%)$. It must be taken into account that the lesser BA does not imply that these latter samples have a lesser blood cholesterol-lowering effect, since other intervening mechanisms have been described apart from competition for incorporation into micelles, such as the co-crystallization of PS plus cholesterol in the intestinal tract, followed by precipitation. These results therefore should be complemented by in vivo assays to allow better assessment of their functionality.

In general, our samples showed a greater BA of total PS than in PS-enriched milk beverages reported by Alemany et $a l .{ }^{19}(3 \%)$, as well as a greater BA of the individual PS. In addition, the BA for campesterol (19\%), $\beta$-sitosterol (17\%) and sitostanol (13-14\%) was the same in samples $\mathrm{A}$ and B. However, in the study published by Alemany et al. ${ }^{19}$ which described the same order of PS abundance as in our work $(\beta$-sitosterol $>\beta$-sitostanol $>$ campesterol), the BA of campesterol $(4 \%)>$ stigmasterol $=\beta$-sitosterol $($ approximately $3 \%)$. It should be noted that in our study samples A and B were enriched with double the amount of PS as in the publication by Alemany et al. ${ }^{19}$ (0.8 g per $100 \mathrm{~mL}$ ), and the fact that fermented milk was involved may have contributed to greater BA.

The BA for total PS of sample C was $9 \%$, with the same value as for the individual PS. The protein, lipid and PS contents of beverage $\mathrm{C}$ were similar to those found in samples A and $\mathrm{B}$, with differences in terms of the PS profile and the fact that carbohydrates were 3-4 times more abundant in sample C (see Table 1). In sample D, with the same BA for total PS as sample C, campestanol and sitostanol showed the highest BA $(12 \%$ and $11 \%$, respectively) $>\beta$-sitosterol $(6 \%)$, and this sample also had the highest lipid and fiber contents (Table 1). However, there are no data in the literature on the influence of carbohydrates, lipids and fiber upon the BA of PS. In this sense, it is well known that fiber can affect the incorporation of carotenoids into the mixed micelles thus decreasing their $\mathrm{BA}^{33}$ and so, the same effect can be expected for PS. Regarding the matrix effect on the BA of PS, little is known. In this regard, Alemany et al. ${ }^{19}$ reported better BA in two (with and without tangerine fruit juice) low-fat fruit-milk beverages $(4-6.5 \%)$ than in fruit or milk beverages (3\%), reflecting an important matrix effect, moreover, the presence of $\beta$-cryptoxanthin in the fruit-milk beverages significantly reduces the BA of PS. On the other hand, in the in vivo study by Clifton $e t$ al. $(2004),{ }^{13}$ a matrix effect was also observed since they found a higher LDL-cholesterol reduction exerted by dairy products than cereal products. Specifically, a major response was 
obtained with milk, containing $1.4 \%$ fat, and $6 \%$ carbohydrates, than with yoghurt, $1.6 \%$ fat, $14.7 \%$ carbohydrates, whereas cereal products contain $5.8-7.6 \%$ fat and $40.5-54.5 \%$ carbohydrates. Therefore, the similarity of food matrix effects observed between our in vitro and the latter in vivo study would point out the validity of a simulated gastrointestinal digestion as a preliminary tool to test the PS-enriched food functionality.

On considering the BA of $\beta$-sitosterol/sitostanol in the samples, it is seen that although the sitostanol content is about 10 times higher in sample D than in samples A and B, this circumstance had no impact upon BA. In contrast, in the case of $\beta$-sitosterol, the lesser content found in samples $\mathrm{C}$ and $\mathrm{D}$ indeed resulted in a marked decrease in BA.

\section{Conclusions}

In this study, the BA of total and individual PS of four commercial PS-enriched fermented milk beverages was evaluated using in vitro gastrointestinal digestion. The results obtained in our study corroborate the importance of the matrix, in addition to the PS source ingredient used, in defining PS release from the matrix and its competition with cholesterol for incorporation into the intestinal micelles, resulting in the desired blood cholesterol-lowering effect. This circumstance is reflected in the analyzed samples with different BA.

The results obtained demonstrate the need for further both in vitro and in vivo studies of each PS-enriched product before marketing, in order to establish its efficacy, since many factors such as the food matrix and PS source ingredient intervene in determining the bioavailability. This fact should be taken into account by the food industry in the development of PSenriched food products to maximize the functionality.

\section{Abbreviations}

$\begin{array}{ll}\text { BA } & \text { Bioaccessibility } \\ \text { BF } & \text { Bioaccessible fraction } \\ \text { BHT } & \text { Butylhydroxytoluene } \\ \text { BSA } & \text { Bovine serum albumin } \\ \text { EAS } & \text { European Atherosclerosis Society } \\ \text { HMDS } & \text { Hexamethyldisilazane } \\ \text { IS } & \text { Internal standard } \\ \text { KCl } & \text { Potassium chloride } \\ \text { KOH } & \text { Potassium hydroxide } \\ \text { Opm } & \text { Orbits per minute } \\ \text { PS } & \text { Plant sterols } \\ \text { TMCS } & \text { Trimethylchlorosilane } \\ \text { TMSE } & \text { Trimethylsilyl ether }\end{array}$

\section{Acknowledgements}

This study was partially financed by Consolider Fun-C-Food CSD 2007-00063. The authors are participants in the FA1005 COST Action INFOGEST on food digestion.

\section{Notes and references}

1 G. García-Llatas and M. T. Rodríguez-Estrada, Chem. Phys. Lipids, 2011, 164, 607-624.

2 H. Gylling, J. Plat, S. Turley, H. N. Ginsberg, L. Ellegård, W. Jessup, P. J. Jones, D. Lütjohann, W. Maerz, L. Masana, G. Silbernagel, B. Staels, J. Borén, A. L. Catapano, G. De Backer, J. Deanfield, O. S. Descamps, P. T. Kovanen, G. Riccardi, L. Tokgözoglu and M. J. Chapman, Atherosclerosis, 2014, 232, 346-360.

3 O. Weingärtner, R. Baber and D. Teupser, Biochem. Biophys. Res. Commun., 2014, 446, 811-813.

4 Regulation 983/2009/EC. Off. J. Eur. Union, 2009, L277, 3-12.

5 Regulation 432/2012/EC. Off. J. Eur. Union, 2012, L136, 1-40.

6 Regulation 686/2014/EC. Off. J. Eur. Union, 2014, L182, 27-30.

7 D. S. MacKay and P. J. H. Jones, Eur. J. Lipid Sci. Technol., 2011, 113, 1427-1432.

8 E. De Smet, R. P. Mensink and J. Plat, Mol. Nutr. Food Res., 2012, 56, 1058-1072.

9 T. Lubinus, A. Barnsteiner, T. Skurt, H. Hauner and K. H. Engel, Eur. J. Nutr., 2013, 52, 997-1013.

10 S. S. AbuMweis, R. Barake and P. J. H. Jones, Food Nutr. Res., 2008, 52, 1811-1821.

11 L. K. Cusack, M. L. Fernandez and J. S. Volek, Adv. Nutr., 2013, 4, 633-643.

12 G. Garcia-Llatas, A. Cilla, A. Alegría and M. J. Lagarda, J. Funct. Foods, 2015, 14, 44-50.

13 P. M. Clifton, M. Noakes, D. Sullivan, N. Erichsen, D. Ross, G. Annison, A. Fassoulakis, M. Cehun and P. Nestel, Eur. J. Clin. Nutr., 2004, 58, 503-509.

14 A. M. E. Doornbos, E. M. Meynen, G. Duchateau, H. C. M. van der Knaap and E. A. Trautwein, Eur. J. Clin. Nutr., 2006, 60, 625-333.

15 F. Granado-Lorencio, M. J. Lagarda, F. J. Garcia-López, L. M. Sánchez-Siles, I. Blanco-Navarro, A. Alegría, B. Pérez-Sacristán, G. Garcia-Llatas, E. Donoso-Navarro, R. A. Silvestre-Mardomingo and R. Barberá, Nutr. Metab. Cardiovasc. Dis., 2014, 24, 1090-1096.

16 M. González-Larena, G. García-Llatas, M. C. Vidal, L. M. Sánchez-Siles, R. Barberá and M. J. Lagarda, J. Agric. Food Chem., 2011, 59, 3624-3631.

17 M. Minekus, M. Alminger, P. Alvito, S. Ballance, T. Bohn, C. Bourlieu, F. Carriere, R. Boutrou, M. Corredig, D. Dupont, C. Dufour, L. Egger, M. Golding, S. Karakaya, B. Kirkhus, S. Le Feunteun, U. Lesmes, A. Macierzanka, A. Mackie, S. Marze, D. J. McClements, O. Menard, I. Recio, C. N. Santos, R. P. Singh, G. E. Vegarud, M. S. J. Wickham, W. Weitschies and A. Brodkorb, Food Funct., 2014, 5, 11131124.

18 M. I. Moran-Valero, D. Martin, G. Torrelo, G. Reglero and C. F. Torres, J. Agric. Food Chem., 2012, 60, 11323-11330.

19 L. Alemany, A. Cilla, G. García-Llatas, M. T. RodriguezEstrada, V. Cardenia and A. Alegría, Food Res. Int., 2013, 52, 1-7. 
20 G. Garcia-Llatas, A. Cilla, L. Higueras, M. Pons, S. Ripollés, C. Bañuls and M. J. Lagarda, Int. J. Dairy Technol., 2013, 66, 437-448.

21 M. González-Larena, A. Cilla, G. García-Llatas, R. Barberá and M. J. Lagarda, J. Agric. Food Chem., 2012, 60, 47254734.

22 J. Folch, M. Lees and G. H. Sloane-Stanley, J. Biol. Chem., 1957, 226, 497-509.

23 R. Santos, E. Limas, E. M. Sousa, M. da Conceição Castilho, F. Ramos and M. I. Noronha da Silveira, Food Chem., 2007, 102, 113-117.

24 F. Granado-Lorencio, B. Olmedilla-Alonso, C. HerreroBarbudo, I. Blanco-Navarro, B. Pérez-Sacristán and S. Blázquez-García, Food Chem., 2007, 102, 641-648.

25 D. Saraiva, M. da Conceição Castilho, M. do Rosário Martins, M. I. Noronha da Silveira and F. Ramos, Food Anal. Methods, 2011, 4, 28-34.
26 R. Inchingolo, V. Cardenia and M. T. Rodriguez-Estrada, J. Sep. Sci., 2014, 37, 2911-2919.

27 A. Barnsteiner, R. Esche, A. Di Gianvito, E. Chiavaro, W. Schmid and K. H. Engel, Food Control, 2012, 27, 275283.

28 P. Laakso, Eur. J. Lipid Sci. Technol., 2005, 107, 402410.

29 Decision 335/2004/EC, Off. J. Eur. Union, 2004, L105, 46-48.

30 Decision 336/2004/EC, Off. J. Eur. Union, 2004, L105, 49-51.

31 Regulation 258/1997/EC, Off. J. Eur. Union, 1997, L43, 1-6.

32 European Food Safety Authority (EFSA), EFSA J., 2008, 133, $1-21$.

33 P. Etcheverry, M. A. Grusak and L. E. Fleige, Front. Physiol., 2012, 3, 1-22. 